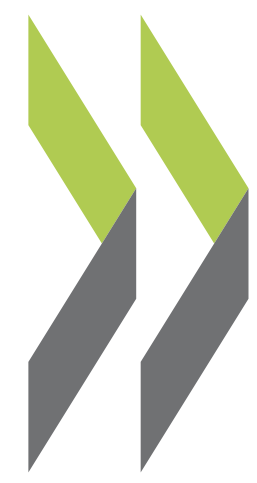

PEB Exchange, Programme on Educational Building 2005/13 


\section{SCHOOL GROUNDS IN AUSTRIA}

The Austrian Institute for School and Sport Facilities (ÖISS), responsible for providing the country with guidelines, information and consultation in the field of school building, places special emphasis on school grounds. The ÖISS works to raise awareness of the importance of school grounds not only for physical activities and recreation, but also for learning, communication and the environment.

Directives for designing school grounds cover all outdoor areas used both during and outside school hours, whether for classes or free time activities. Public areas and other available spaces used by schools should also be considered when designing school facilities.

When schools are newly built, renovated or enlarged in Austria, the provision of school grounds must be examined and improved if possible. The quality of school grounds is increasingly important as space devoted to activities for children and adolescents are continually reduced in residential areas. And grounds can serve to combat difficulties students may face such as health problems, a lack of social skills, aggressive behaviour and physical disabilities.

Designing school grounds is a significant part of the planning process and thus must be done at an early stage and by experts.

To guarantee quality, the experts must take into account the following factors and apply them under the principle of sustainable development: user participation, multi-use, safety and security, building without barriers, gender mainstreaming, sports, recreation, communication, learning zones, multi-functionality, multi-use, nature and the environment, and flexibility. These factors are materialised through certain organisational requirements, design principles and ecological objectives, described below.

\section{Organisational requirements}

1. Users should participate in the design process.

2. Shared usage of the school grounds should be studied in the planning stage, however sharing facilities with the local community must not infringe on the school's needs. Five to ten square meters of open space should be allotted per student (excluding sports facilities, waste disposal areas and parking). ${ }^{1}$

3. Multifunctional sports facilities can make up for a lack of open space.

4. The use of spaces such as terraces and roof gardens should be examined.

5. The use of public spaces such as parks and of private facilities such as sports clubs should be considered.

6. Austrian safety standards must be respected.

7. Planning must include a suitable maintenance scheme, taking into account the resulting costs.

\section{Design principles}

1. Entrances, the main access to the school grounds and the basic equipment (e.g. swingsets, slides, sandboxes) must be barrier-free.

2. Sufficient seating must be provided for people resting or waiting.

3. Entrance areas should be designed as meeting points and waiting areas.

4. School grounds should offer both active and quiet zones; the different zones should be adapted to the users' needs, considering differences in age, sex, etc.

5. School grounds should offer individual and collective learning zones for various pedagogical activities.

6. School grounds should have both open zones and retreat areas for different types of experiences and exchanges.

7. The entire schoolyard should allow for a variety of uses, for example through multi-purpose playing fields and multi-functional equipment for outdoor areas.
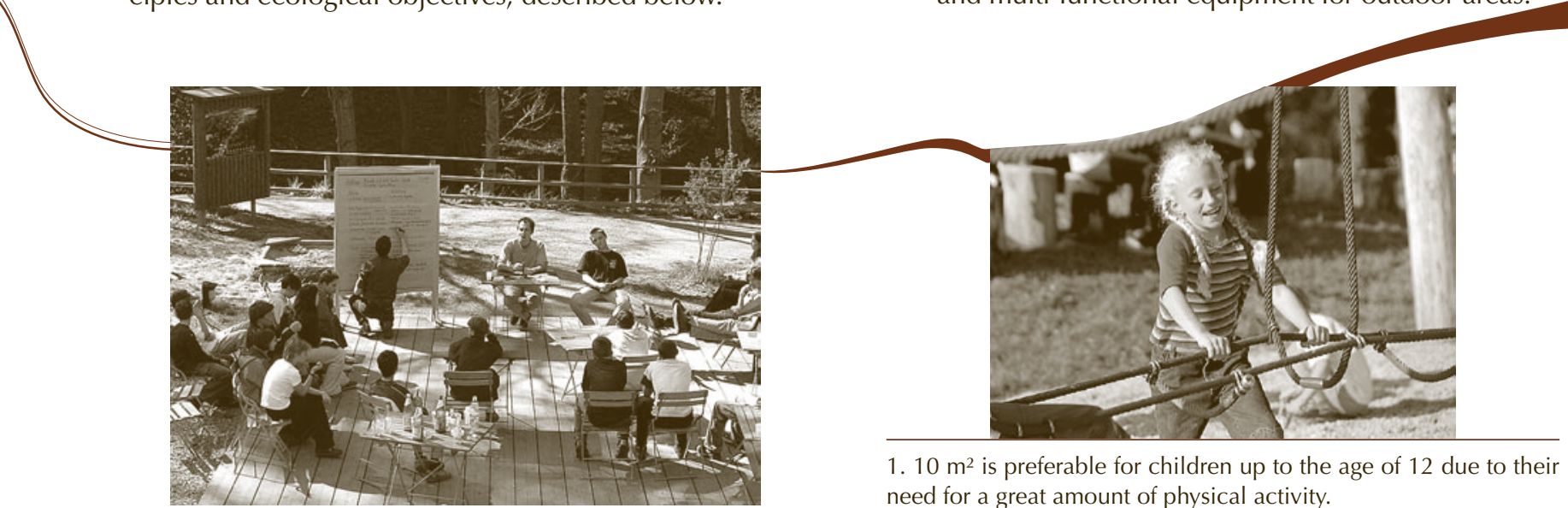

1. $10 \mathrm{~m}^{2}$ is preferable for children up to the age of 12 due to their need for a great amount of physical activity. 


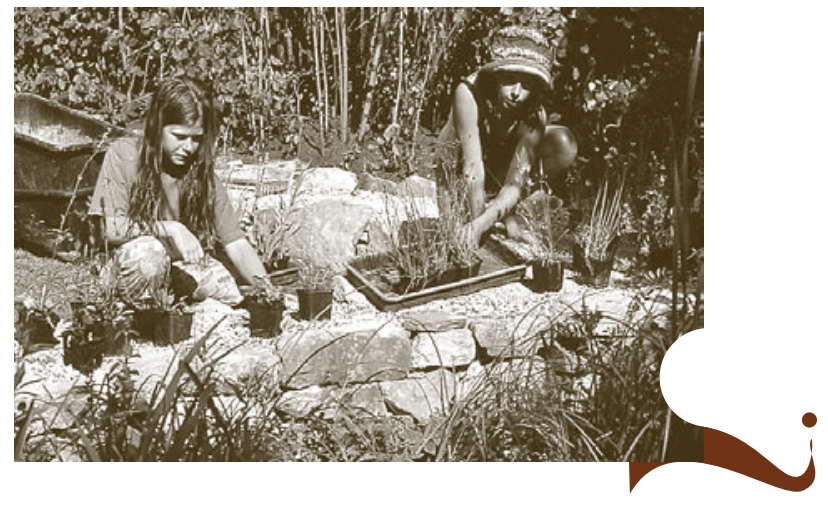

More information on "Current Concerns for Austrian School Facilities" can be found in PEB Exchange no. 49, June 2003.

ÖISS would welcome comments on these school grounds directives. Please write to Karin Schwarz, e-mail: schwarz@oeiss.org.

8. School grounds should be designed to accommodate celebrations, exhibitions, performances and similar events.

9. School grounds should comprise areas suitable for change and for new interpretation by future generations of students and teachers. The planned elements should leave room for further development.

10. The users should have possibilities to observe and experience nature.

11. Mobile equipment is a useful element for flexible school grounds, and appropriate storage facilities should be included in the design.

\section{Ecological objectives}

1. The existing vegetation should be retained if possible.

2. The possibility of re-using existing building materials and the existing substratum should be studied (reducing costs for transport, materials and disposal).

3. Rainwater should stay on the property and should be used if possible.

4. When possible, vegetation should be planted to cover roofs and façades (to reduce dust, moisture damage and noise; to provide insulation; and to provide natural habitats).

5. Maintenance does not have to be large-scale, rather it should be in harmony with nature.

6. Plants should be chosen according to the local habitat, and native species should be given priority.

More details and a checklist on planning measures can be found in the study "school:FREE"; ${ }^{2}$ additional studies and publications on this topic are available in German at www.schulfreiraum.com.

2. Mellauner, Michl and Liette Clees (ed.) (2004), "school:FREE - Recommendations for the Design of School grounds", a study carried out on behalf of ÖISS, BIG (Federal Real Estate Company) and the Austrian Federal Ministry for Education, Science and Culture (BMBWK) by the Institute of Landscape Architecture, Department for Space, Landscape and Infrastructure of the Universität für Bodenkultur (University of Natural Resources and Applied Life Sciences), Vienna. Available at www.oeiss.org., in English and German.

\section{AN URBAN RENEWAL SCHOOL PROJECT IN ITALY}

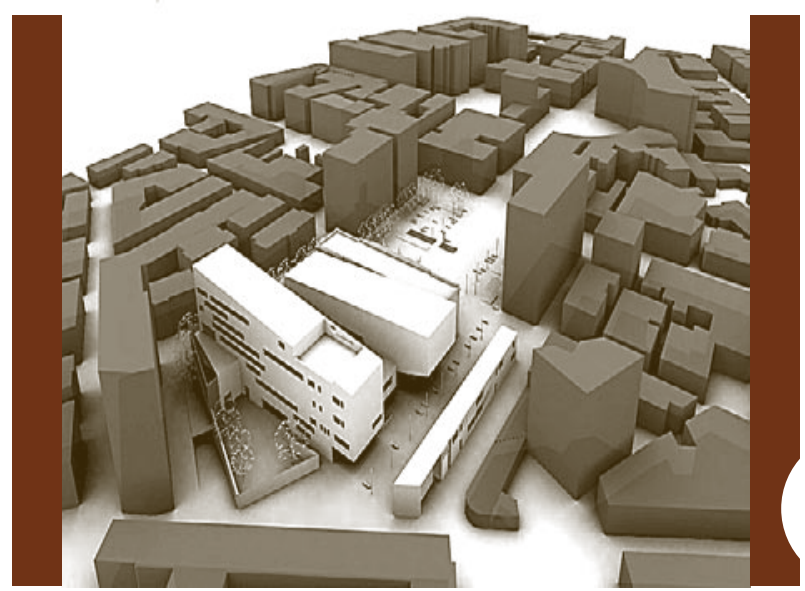

The restoration of an historic school building in Battipaglia, Italy, will provide new public facilities and is hoped to boost urban renewal. The municipality of Battipaglia, in the province of Salerno, held an architectural competition for renovating the E. De Amicis Primary School and the surrounding area. The winning project, submitted by a group of Italian architects headed by Alfredo Amati, offers four main points of interest:

- The use of a school building to promote broader urban renewal.

- The integrated planning of various services within a multifunctional architectural complex.

- High architectural quality.

- Flexibility and versatility.

The project is based on a comprehensive concept for the urban and architectural renewal of the area around the E. De Amicis School. Authorities hope the project will launch a process of linking together the adjacent existing buildings into a unified neighbourhood. 